\title{
Light: a project, a format, a method, an event
}

\author{
Rossella Palomba
}

Do you hold stereotypes? If you answer "No" to this question, then you probably do hold a lot, and use them all the time, without knowing it. Stereotyping is a fundamental process of the human mind through which our brain can easily stock a large amount of information; it involves oversimplification and overgeneralization, because you apply to all the members of a group the characteristics that you have learned to associate to that group either by meeting one or a few of its members or from parents, peers, the internet or the media.

There are three main reasons why nobody is free from stereotyping: stereotyping is efficient from a cognitive point of view, because you no longer need information about an individual

How to cite this book chapter:

Palomba, R 2017 Introduction. Light: a project, a format, a method, an event. In: Tintori, A and Palomba, R. Turn on the light on science, Pp. vii-xvi. London: Ubiquity Press. DOI: https://doi.org/10.5334/bba.a. License: CC-BY 4.0 
if you are aware that he or she is a member of a specific group; and it is reassuring, because you feel better about yourself, in the case where you hold pejorative attitudes towards those who are different.

As noted by Kahneman, we have two modes of thinking: the fast mode and the slow mode. The fast mode operates automatically and quickly, with little or no effort and no sense of voluntary control; the slow mode allocates attention to the effortful mental activities that demand it and to situations where you are asked to do something that does not come naturally. Because you have a limited amount of attention that you can allocate to the various activities, actions, tasks or problems that fill up your life, stereotyping represents an automatic easy reaction to a complex world (Kahneman 2011).

You stereotype people every time you are unable to obtain and/ or understand all of the information needed to make a reasonable judgement about them, their professions, or their goals. Many authors (see for example Ramirez-Berg 2002; Sosnizkij 2003; and Ndom, Elegbeleye and Williams 2008) have observed that in the absence of the so-called "total picture", stereotyping the members of groups allows you to fill in the missing pieces of information.

Breaking down stereotypes that are established over time - and possibly reinforced by the media and internet - is not an easy task. Part of it involves becoming conscious of holding these stereotypes: if you are aware of your hidden biases, you can monitor and attempt to change your attitudes. It may not be possible to avoid the automatic stereotype or prejudice, but it is certainly possible to consciously amend it. In situations in which information about a particular target group is clear, relevant and highly informative, the stereotypes we hold also mean much less and 
become irrelevant. On the other hand, when personally obtained information is absent, or is ambiguous, people do rely on the stereotypes they hold. Obviously the problem of stereotype removal cannot be solved by simply explaining that your attitudes are based on a wrong image of reality: no matter what we say, you will be inclined to hold your beliefs intact.

Bearing this in mind, we can raise the second and - for this book - more relevant question: do you stereotype scientists? Here you will probably answer: "Don't know", or "I never thought about it". You are not the only one who never considered the possibility of holding stereotypes about scientists and their work. Scientists themselves rarely think about it: often they do not care about the potentially biased image people have of them, or simply do not make any effort in conveying the correct image of their profession because "it is not their task".

If one asks scientists why they decided to embark on a scientific career, they will most probably answer that it is a privilege to be immersed in a world as stimulating as science is, or that they like dedicating their life trying to understand how the world works. By answering in this way, they perpetuate and reinforce the stereotype that scientists are somehow "different" from ordinary people - and anyone who is different, is immediately suspect.

Contrary to what is the case with many other professions such as those of medical doctors, pharmacists or lawyers, one very rarely has the chance to meet a real, flesh-and-blood scientist. As reported by Deloitte (2015), in the EU-28 there are 1.63 million researchers (in Full Time Equivalent), who account for less than 0.7 per cent of the total labour force. In other words, the chance to meet one of them or to have a scientist among your group of friends or neighbours, unless you are yourself a scientist, is very low. This makes it very difficult for you to review your ideas about 
scientists, to become conscious of your own biases, and to move beyond them.

The world is increasingly reliant on science, and yet a large portion of the general public has a wrong image of scientists and their work. We are all aware that science is taking quick steps forwards, that scientific results have an immediate and tremendous impact on our daily lives, and that the future is closer than we imagined. Therefore it very relevant for our societies that the image of those who produce this fantastic progress, i.e. scientists, be positive, attractive, inspiring and unbiased. Changing the public image of scientists, closing the gap between science and the wider society and developing new and simpler ways to communicate science produces a deeper consciousness of the relevance of science for our societies and a growing attractiveness towards scientific jobs.

Since 2005 the European Commission has committed itself "to enhance [the] public recognition of researchers and their work". The tool identified for achieving that goal was the organization of the European event called Researchers' Night, held during the same night in many European towns. The main objective of this action was "to bring researchers closer to the larger public, with a view to enhancing their important role in society, and in particular within the daily life of citizens" (European Commission 2007b, p. 25 ).

Every year, the European Commission launches a call for proposals under the framework of the Marie Skłodowska-Curie Actions programme in order to give funds for the organization of Researchers' Nights all over Europe. In the annual calls for proposals for the Researchers' Nights, stereotypes and the possibility to tackle them was mentioned among the expected impacts; we therefore immediately understood the importance of such events for testing our ideas on how to let people break down the stereotypes they hold about scientists. 
In answering the call for proposals, the basic idea of many organizers of the Researchers' Nights held around Europe is that science is so rich and has such deep content that putting scientists on stage and letting them talk or do funny experiments with people is enough to leave the attendees enchanted by science and scientists. This idea is true, but do people change their opinion about scientists? Do they break down the stereotype that researchers are highly gifted individuals, smart geniuses, with superior abilities to reason, generalize or problem-solve, and somehow above everyone?

Our project, called Light: Turn on the light on science (hereafter Light), had exactly the aim of undoing the stereotypes about scientists; it consisted of a big field test carried out in Italy that involved more than 100,000 people over several years. In this book we present the results of the 2013 edition of Light (Light'13), which was our last proposal funded by the European Commission (we started in 2008) and the final outcome of six years of testing, adjusting and confirming hypotheses on how it is possible to undo the stereotypes concerning scientists and their work.

This book is not just about organizing events: we wanted to change the stereotype of a scientist. In order to comply with the European Commission's rules about Researchers' Night, we had to do so during a science communication event, and our event, which took place over a few hours and in one location, attracted 15,000 people. This is different from organizing a talk with a scientist at a school or a science café, with a limited number of people discussing with researchers.

There was no doubt that between the two fundamental models used in science communication, i.e. "deficit" or "dialogue" approaches, we had to choose the latter. In fact, in the deficit approach the audience members are assumed to lack the necessary 
knowledge about scientific concepts, and therefore communication goes from scientists to the public, reinforcing the idea that scientists are special people who work on things that "you people wouldn't believe", just to quote from the famous movie Blade Runner (1982). Conversely, in the dialogue approach there is a twoway exchange of information between scientists and the public: scientists have scientific facts and experience at their disposal and the members of the public have personal interests in the scientific experiments presented.

But is simple interaction enough to let people catch a glimpse of the human side of a scientist? Can the dialogue between scientists and the public go beyond an enthusiasm for science and result in a change in attitudes towards scientists? Interaction and dialogue are necessary but not sufficient conditions for obtaining such a change.

To reach our goal, we started by drawing a list of the most common images people have of scientists, mainly conveyed by TV series or movies. For example, if we talk about a chemist you probably picture a middle-aged male, wearing a white lab coat and mixing up strange liquids in strange glass bottles. And a physicist may be a guy who looks like Einstein, with no social skills, playing with risky equipment all the time. In the first chapter of this book, through a review of recent literature, you will be equipped with all the necessary information on the most common stereotypical images of scientists, held by ordinary people. Results from surveys carried out at IRPPS-Research Institute on Population and Social Policies and in similar institutions will also be presented.

In order to let people abandon the idea that scientists are dispassionate geniuses, somehow above ordinary people, we thought that the first step should be to remove any barrier, material or psychological, that could impede a fluent and real interaction 
between scientists and the public. The set-up of a location can have a tremendous impact on people's emotions and attitudes. Such impact has been analysed and studied to create friendly working environments, for example, but very few social scientists have paid attention to architecture and design with a view to remove the communication barriers that are built up between the public and researchers simply by using the materials at disposal (desks, chairs, microphones etc.).

We started a partnership with architects and designers in order to create an innovative set-up of the location where we wanted the public to meet researchers. 'The Light: Turn on the light on science' project was a consortium of two partners: the Italian National Research Council (CNR) and Triplan Ltd, a private architecture, design and communication firm. Architects working in the public realm are continually collaborating with experts to enable a design to be transferred from paper to a fully functioning scheme. We transferred that method to stereotypes' removal. At the conceptual stage, we exchanged ideas and opinions and discussed the possibilities offered by existing materials, with the objective of getting the architects to design a package that responded to our need of undoing the stereotypes about scientists and that at the same time made for an attractive environment for users.

Additionally, in order to let the public catch a glimpse of the human side of researchers, we created a special entertainment space called the Globe Science Theatre where scientists performing arts or doing sports entertained the public. The aim was to show what a scientist does when a scientist is not doing science and overall to demonstrate that scientists do have hobbies, that some of them do these hobbies in a very professional way and that none of them spend all their time trapped in their labs. 
Finally, we created specific activities aimed at addressing the gender stereotypes affecting the situation of women in science. In our experience, talks, data, role models' speeches, posters or exhibits have no permanent effect on people's minds. Gender stereotypes are very deeply rooted and even female scientists do not fully understand how much gender bias informs the decisionmaking and behaviour in their scientific labs or institutions. Our collaboration with the architects was crucial in this respect: we organized a number of sensory experiences where people could have a first-hand experience of gender differences in science through their own senses, i.e. by participating and not just by listening or watching.

The set-up of the event mentioned above will be described and explained in greater detail in Chapter 2. We will also include a list of practical suggestions resulting from our experience. In reading it, you will learn what we did and how you might re-create the conditions to make people review their opinions about and attitudes towards researchers.

As observed by Bultitude (2011), one crucial factor when working with groups from the general public is that the groups are not homogeneous: each person has his or her own interests, prejudices and concerns. Among all possible subgroups of the socalled "general public", we were particularly interested in changing the attitudes towards scientists of young people in order to let them embark on a scientific career. Specific activities were set up based on a peer-to-peer interaction between young inventors, who were students still going to school, and young people in general, in order for them to develop the self-confidence needed to get into science, engineering and technology and to turn it into a "cool" career. We organized a national competition inspired by the television music competition The X Factor. The difference 
was in content: no music, but creativity and inventions realized at school. Chapter 3 deals with this aspect of the project and gives some practical suggestions about how to replicate the initiative.

The final chapter presents the results of surveys we did among people participating in our events and the evaluation of their change of opinions about researchers through the activities we presented.

This book presents a research-based guide on how to break down stereotypes about scientists and science. It is intended for a wide audience with no formal training in science or engineering. Our intention is to raise awareness of how stereotypes affect people's image of scientists and science and help people self-correct, and thereby reduce the negative effects of stereotypes on people's minds. Stakeholders and managers of scientific institutions, who are increasingly conscious of the relevance of communicating research results directly to the greater public and want to overcome the cultural barriers existing between scientists and laypeople, may also find new ideas in this book. Our work may also be of help to educators seeking to protect themselves against negative stereotypes about science careers, to adopt a growth mindset in encouraging students' life aspirations and choices in the fields of Science, Technology, Engineering and Mathematics (hereafter STEM) and to combat gender stereotypes. Finally, the book should also appeal to scientists looking for ways to better their communication skills, and invites them to reflect on the negative impact of a strict "academic" behaviour on the general public and young people in particular. A self-evaluation is therapeutic from time to time to correct behaviour and communicate scientific results to the greater public correctly.

Now is a good time to expand opportunities for scientists and non-scientists to interact and understand each other in formal, 
non-formal and informal settings. In 2014, the European Commission launched a new seven-year strategy on Responsible Research and Innovation (RRI), a cross-cutting issue of the new framework programme Horizon 2020. As stated by the European Commission (n. d.), the objective of RRI is "to build effective cooperation between science and society, to recruit new talent for science and to pair scientific excellence with social awareness and responsibility". In light of this new European vision, stereotypical images of scientists and science should be removed and there is a need to find practical solutions to facilitate the dialogue between scientists and citizens.

This book is a step forward in this direction. Perhaps it is the right book at the right time to make at least a small difference in suggesting how we can change people's minds towards scientists and their work. But let us be frank from the start: there is no one recipe for removing stereotypes about scientists. In this book we will present the path we followed, as what we did can help to better understand what kinds of activism are likely to be effective. 